\title{
Characteristics of Lapsed German Whole Blood Donors and Barriers to Return Four Years after the Initial Donation
}

\author{
Christian Weidmann ${ }^{a *}$ Michael Müller-Steinhardt ${ }^{\mathrm{b}, \mathrm{c} *}$ Sven Schneider ${ }^{\mathrm{a}}$ Eberhard Weck $^{\mathrm{b}, \mathrm{c}}$ \\ Harald Klüter ${ }^{\mathrm{b}, \mathrm{c}}$ \\ ${ }^{a}$ Mannheim Institute of Public Health, Medical Faculty Mannheim, University of Heidelberg, \\ ${ }^{b}$ German Red Cross Blood Service Baden-Württemberg - Hessen, \\ ${ }^{\mathrm{c}}$ Institute of Transfusion Medicine and Immunology, Medical Faculty Mannheim, University of Heidelberg, Mannheim, Germany
}

\section{Keywords}

Blood donation · Lapsed donors · Donor return . Barriers

\section{Summary}

Background: The aim of the study was to identify characteristics of lapsed donors 4 years after the initial donation as well as self-reported barriers to return for further blood donations. Methods: A random number of 8,000 blood donors, donating for the German Red Cross Blood Service Baden-Württemberg - Hessen, were asked to fill in a self-administered questionnaire. The response rate was $38.5 \%$. Donors were categorized as 'lapsed' if they had not donated within the last 24 months. The odds of being a lapsed donor were determined in a multivariate logistic regression. Results: Multivariate analysis showed that lapsed donors were more likely to be female, between 26 and 33 years old, not employed, have moved, and were dissatisfied with the last donation experience. Furthermore, lapsed donors were less likely to have family members or friends who also donate blood. Medical reasons and having moved to another city were the most frequently named reasons preventing lapsed donors from continuing to donate blood. Conclusion: The importance of medical reasons and having moved was rated much higher than in previous studies. We conclude that barriers to return may vary considerably between countries and blood services. Therefore, donor surveys are required to guide reactivation campaigns.

*Both authors contributed equally to this work.

\section{Schlüsselwörter}

Blutspende - Inaktive Blutspender . Erneute Blutspende . Hindernisse

\section{Zusammenfassung}

Hintergrund: Ziel dieser Studie war es, inaktive Blutspender, vier Jahre nach ihrer ersten Spende näher zu charakterisieren und mögliche Hindernisse zu identifizieren. Methoden: Einer Stichprobe von 8000 Spendern des DRK-Blutspendedienstes Baden-Württemberg - Hessen wurde ein schriftlicher Fragebogen zugesandt, der von $38,5 \%$ der Spender ausgefüllt wurde. Spender, die länger als 24 Monate nicht gespendet hatten, wurden als inaktiv gewertet. Die zentralen Hindernisse für weitere Spenden unter inaktiven Spendern wurden beschrieben und Einflussgrößen eines inaktiven Spenderstatus mit Hilfe eines logistischen Regressionsmodells bestimmt. Ergebnisse: Die multivariaten Auswertungen zeigen, dass inaktive Spender häufig weiblich, zwischen 26 und 33 Jahre alt, nicht erwerbstätig, umgezogen und unzufrieden mit ihrer letzten Spendeerfahrung waren. Spender, die im Freundes- oder Verwandtenkreis Kontakt mit aktiven Spendern hatten, waren dagegen seltener inaktiv. Medizinische Gründe und Umzüge wurden von den inaktiven Spendern als häufigste Ursache genannt. Schlussfolgerungen: Medizinische Gründe und Umzüge wurden in früheren Studien als weitaus weniger wichtig bewertet, was auf deutliche Unterschiede in den Merkmalen und Hindernissen von inaktiven Spendern je nach Spendeeinrichtung und Untersuchungsland schließen lässt. Diese Unterschiede unterstreichen die Bedeutung von Spenderbefragungen zur Optimierung von Reaktivierungsbemühungen inaktiver Spender.

\begin{tabular}{ll}
\hline KARGER & ( ) 2012 S. Karger GmbH, Freiburg \\
$1660-3796 / 12 / 0391-0009 \$ 38.00 / 0$ \\
Fax +49 761 452 07 14 & Accessible online at: \\
Information@Karger.de & www.karger.com/tmh \\
www.karger.com &
\end{tabular}




\section{Introduction}

Most developed countries are currently facing a significant change in their demographic structure with major implications for blood supply. While the number of eligible whole blood (WB) donors is declining, the demand for blood products is increasing continuously due to the aging process of these societies [1]. To avoid future blood shortages, the mobilization of the healthy part of the population presently not donating blood as well as the reactivation of lapsed donors that have not donated in the past years is therefore becoming increasingly important [2]. A previous study showed, however, that people presently not donating blood and lapsed donors differ according to sociodemographic characteristics and in their reasons for not donating [3]. Reactivation of lapsed donors therefore requires tailored recruitment strategies that may differ from mobilization campaigns for people who have never donated blood before. To optimize these reactivation strategies, it is crucial to elucidate sociodemographic characteristics of lapsed donors and identify motivational factors deterring them from further blood donations.

In recent years, a number of studies have attempted to identify characteristics of lapsed donors as well as barriers for returning. These studies showed that lapsed donors were more likely to be female, younger, better educated, less satisfied with the last donation and less interested in incentives than donors who donate regularly $[4,5]$. The risk of becoming a lapsed donor increases if donors received only few invitations to donate blood, have a blood group other than $\mathrm{O}$ and live in neighborhoods that have a low average income or are ethnically diverse [5]. Furthermore, donors who were temporarily deferred or showed mild or severe reactions at their last WB donation were more likely to stop donating $[6,7]$. Accordingly, medical reasons were often stated by lapsed donors as barriers to further blood donations [3, 8]. Further important barriers to donate blood were the lack of a convenient place to donate, fear of needles or contradicting diseases, lack of time, limited opportunities to donate, bad treatment, and poor staff skills [3, 9-11].

A detailed analysis of Canadian donors showed that the characteristics and barriers of lapsed donors may be influenced by the donation history [4]. The higher risk of women to lapse appeared only among repeat blood donors, whereas the association with education was only significant for first-time (FT) donors. Nevertheless, most of the previously published studies do not consider the donation history or the number of previous WB donations $[3,5]$. This makes it difficult to tailor donor reactivation strategies as characteristics and barriers of lapsed donors are likely to be influenced by this.

Several studies showed that the risk of becoming a lapsed blood donor is highest at the start of the donor career and decreases significantly after the 3rd or 4th donation [12, 13]. A considerable percentage of lapsed donors at each blood service is likely to have only few donations [5]. Thus, the aim of this study was to determine sociodemographic characteris- tics of lapsed WB donors, who are likely to have only few donations, 4 years after their initial donation as well as to identify self-reported barriers to return for further blood donations.

\section{Material and Methods}

\section{Study Population}

The German Red Cross Blood Service Baden-Württemberg - Hessen collects approximately $85-90 \%$ of all WB donations in southwest Germany. In 2009, a random sample study of 8,000 non-remunerated donors, who first donated WB in the year 2005 at the German Red Cross Blood Service Baden-Württemberg - Hessen, was selected. The sampling was performed by extracting donor information from our database, including name, address, age, sex, and the number of all previous WB donations. No information was available on WB donations made at competing blood services or in other federal states than Baden-Württemberg or Hesse. Donors who are permanently deferred were excluded from the database before drawing the sample. A self-administered questionnaire was mailed to the selected donors along with a personalized introduction letter, a data security statement, and a stamped, pre-addressed return envelope. After 5 weeks, a second mailing including a reminder letter, questionnaire, data security statement, and return envelope was send to non-respondents.

\section{Survey Instrument}

The self-administered questionnaire contained 18 questions, including sections on sociodemographic characteristics (7 questions), donation history (1 question), experiences and satisfaction with the first and last WB donation (5 questions), social ties (3 questions) as well as motivation for and deterrents from blood donation ( 2 questions). Study design and questionnaire were positively approved by the local ethic committee (reference number 2009-227E-MA). Donors were categorized as 'lapsed' if they answered that they had not donated within the last 24 months. Lapsed donors were asked to rate the relevance of twelve potential barriers on a five-point scale. The barriers given were adopted from a previous study [9].

Several questions gathered information relevant for describing lapsed donors including age, sex, education, employment, moves during the surveillance period, active donors among friends and relatives, and the number of WB donations during the first 12 months after the initial donation $[4,5,13]$. Satisfaction with the last donation was assessed by 9 questions about different steps of the donation process. Exploratory factor analysis showed that the items were highly correlated and loaded on a single factor. Therefore, a mean satisfaction value of all items was calculated and categorized into tertiles (low, medium, high). Additionally, the participants were asked, on a five-point scale, how they felt physically at the last donation. The ratings were categorized into low (very bad, bad, fair), medium (good), and high (very good).

Finally, two indicator variables were included to minimize bias due to donations at other blood services. The first one identifying donors who have donated at least once outside the federal states of Baden-Württemberg or Hesse and the second one identifying donors living close to a competing blood service and could have donated there. This variable was generated using the zip codes of each respondent [14]

\section{Statistical Analysis}

The proportion of lapsed donors who had not donated within the last 24 months was calculated amongst the participants of the donor survey. This was followed by a bivariate analysis during which donor characteristics were set in relation to collected data on lapsed donors. Group differences with regard to the proportion of lapsed donors were tested by the chi-square test. Finally, a multivariate logistic regression was used to compare the odds of being a lapsed donor as a function of several donor characteristics and the satisfaction with the last donation. Donors with missing values in any of the variables were excluded from the analysis. 
Table 1. Response rate of the donor survey in different subgroups

\begin{tabular}{lll}
\hline Variable & Sample size & Percentage participating \\
\hline Total & 8,000 & 38.5 \\
Age, years & & \\
$\quad 22-25$ & 2,420 & 35.4 \\
$26-33$ & 1,759 & 31.4 \\
$34-43$ & 1,659 & 43.2 \\
$44+$ & 2,126 & 44.0 \\
Sex & & \\
$\quad$ Men & 3,653 & 33.1 \\
$\quad$ Women & 4,347 & 43.0 \\
No of WB donations in the first 12 months $^{\mathrm{a}}$ & \\
$\quad 0$ & 4,039 & 29.8 \\
1 & 2,198 & 43.9 \\
$2+$ & 1,763 & 51.6 \\
\hline after the initial donation. & \\
\hline
\end{tabular}

To describe the relevance of different barriers, the proportion of lapsed donors who rated the barrier as important or very important (value four or five on a five-point scale) was calculated. The analysis was performed separately for three age groups (22-25 years, 26-43 years, and 44-65 years) as previous studies showed that the relevance of barriers to donate may differ with age [15]. Chi-square test was used to test for significant differences between the groups. All tests were conducted two-tailed and $p$ values $<0.05$ were considered statistically significant. The statistical package PASW Statistics 18 (SPSS, Inc., 2009, Chicago, IL, USA) was used for the calculations.

\section{Results}

The self-administered questionnaire was filled in and returned by 3,077 donors correlating to a response rate of $38.5 \%$ according to AAPOR standards [16]. Donors who did not participate in the survey tended to be younger, male, and have donated less frequently after the initial donation than donors who returned the questionnaire (table 1). Due to missing values in any of the variables, 375 donors were excluded from the analysis. Our analytic sample consisted of 2,702 donors with a mean age of 36.5 years.

Among all participants, $29.7 \%$ reported that they had not donated in the past 24 months and were therefore categorized as lapsed. All other participants $(70.3 \%)$ reported that they had donated at least once in the past 24 months and were categorized as active. Bivariate analysis showed that lapsed donors were significantly more likely to be female, between 26 and 33 years old, not employed, have moved several times during the study period, have a high education, and report no further donations in the first 12 months after the initial donation (table 2). Furthermore, lapsed donors were less satisfied with the last donation experience and were more likely to report a feeling of being sick during the last donation. In contrast, lapsed donors were less likely to have family members or friends who donate blood regularly. The access to a competing blood service significantly increases the likelihood to become a lapsed donor in our study, whereas donations in other federal states were considered as not relevant. The multivariate logistic regression confirmed most of the bivariate associations. However, the differences between the education groups were no longer significant when adjusting for all other variables.

Amongst lapsed donors, medical reasons were the most frequently stated reasons preventing donors from continuing to donate blood $(30.9 \%)$ followed by moving away from the area where they used to donate $(18.7 \%)$ (fig: 1$)$. Travel to foreign countries, new jobs or schools, and a feeling of being sick during the last donation were other important reasons (16.3, 13.3 and $13.3 \%$, respectively), whereas 'afraid it hurts', 'treated badly by the staff', and 'dislike the sight of blood' were rated as not important. The evaluation of five barriers showed significant differences between three age groups (donors' age: 22-25, 26-43, and 44-65 years). Medical reasons $(\mathrm{p}<0.01)$ were more important to middle-aged and older donors than to younger donors. In contrast, moves $(\mathrm{p}<0.001)$, travel to foreign countries $(\mathrm{p}<0.001)$, new jobs or schools $(\mathrm{p}<0.001)$, and donations at other blood services $(\mathrm{p}<0.001)$ were rated significantly higher amongst younger lapsed donors.

\section{Discussion}

Donor retention has been described as a major challenge for blood services. Several studies showed, however, that many donors do not donate regularly and lapse after few donations $[12,13]$. This study identified risk factors for becoming a lapsed donor 4 years after the initial donation, considering donor sex, age, employment status, having moved, first year donation frequency, dissatisfaction with the last donation experience, lack of social ties, and the access to competing blood services. Medical reasons, having moved, travel to foreign countries, and new jobs or schools were stated as major reasons preventing lapsed donors from continuing to donate blood.

These results have several implications for blood services that are willing to reactivate donors not having donated within the last 2 years. First of all, a high proportion of lapsed donors have moved to another city, and thus the new mailing address may be unknown. Blood services should therefore check, whether email addresses are available and could be used to reactivate lapsed donors. Online communities for blood donors could be another interesting alternative to stay in contact with donors that have moved to another city and invite them to new donation sites [17].

Our study showed further that many lapsed donors have health concerns that should be addressed in reactivation campaigns. Three out of 10 lapsed donors rated health concerns as important or very important, although our sample did not include any permanently deferred donors. In a previous study on deterrents of lapsed donors, it appeared that many lapsed donors described themselves incorrectly as permanently de- 
Table 2. Study population and profiles of lapsed donors.

\begin{tabular}{|c|c|c|c|c|}
\hline Variable & $\begin{array}{l}\text { Study } \\
\text { population }\end{array}$ & $\begin{array}{l}\text { Percentage } \\
\text { lapsed }\end{array}$ & Bivariate association & $\begin{array}{l}\text { Adjusted odds ratio } \\
(95 \% \mathrm{CI})\end{array}$ \\
\hline Total & 2,702 & 29.7 & & \\
\hline \multicolumn{5}{|c|}{ Donor characteristics } \\
\hline \multicolumn{5}{|c|}{ Age, years } \\
\hline $22-25$ & 740 & 31.6 & $\mathrm{df}=3, \chi^{2}=32.4 * * *$ & reference category \\
\hline $26-33$ & 513 & 36.1 & & $1.32(1.00-1.74)^{*}$ \\
\hline $34-43$ & 617 & 31.3 & & $1.33(1.00-1.76)^{*}$ \\
\hline $44+$ & 832 & 22.6 & & $0.83(0.62-1.10)$ \\
\hline \multicolumn{5}{|l|}{ Sex } \\
\hline Men & 1,069 & 24.6 & $\mathrm{df}=1, \chi^{2}=21.9^{* * *}$ & reference category \\
\hline Women & 1,633 & 33.0 & & $1.23(1.00-1.50)^{*}$ \\
\hline \multicolumn{5}{|l|}{ Education } \\
\hline High & 1,332 & 32.7 & $\mathrm{df}=2, \chi^{2}=13.8^{* * *}$ & reference category \\
\hline Medium & 922 & 28.2 & & $1.13(0.92-1.40)$ \\
\hline Low & 448 & 23.9 & & $1.17(0.88-1.56)$ \\
\hline \multicolumn{5}{|l|}{ Employment } \\
\hline Employed & 2,005 & 26.6 & $\mathrm{df}=1, \chi^{2}=13.8^{* * *}$ & reference category \\
\hline Not employed & 697 & 38.6 & & $1.73(1.40-2.14)^{* * *}$ \\
\hline \multicolumn{5}{|l|}{ Moved } \\
\hline Never & 1,898 & 26.6 & $\mathrm{df}=2, \chi^{2}=50.4^{* * *}$ & reference category \\
\hline Once & 561 & 32.3 & & $1.07(0.84-1.36)$ \\
\hline$>1$ & 243 & 48.1 & & $1.90(1.37-2.63)^{* * *}$ \\
\hline \multicolumn{5}{|c|}{ Number of WB donations in the first 12 months $^{\mathrm{a}}$} \\
\hline 0 & 1,057 & 46.7 & $\mathrm{df}=2, \chi^{2}=293.0 * * *$ & reference category \\
\hline 1 & 832 & 26.7 & & $0.45(0.37-0.55)^{* * *}$ \\
\hline $2+$ & 813 & 10.6 & & $0.15(0.12-0.20)^{* * *}$ \\
\hline \multicolumn{5}{|l|}{ Last donation } \\
\hline \multicolumn{5}{|c|}{ Satisfaction with last donation } \\
\hline High & 1,003 & 25.4 & $\mathrm{df}=2, \chi^{2}=20.7 * * *$ & reference category \\
\hline Medium & 909 & 29.5 & & $1.12(0.89-1.41)$ \\
\hline Low & 790 & 35.3 & & $1.46(1.16-1.85)^{* *}$ \\
\hline \multicolumn{5}{|c|}{ Physically felt after last donation } \\
\hline High & 1,094 & 20.0 & $\mathrm{df}=2, \chi^{2}=159.6^{* * *}$ & reference category \\
\hline Medium & 1,164 & 30.1 & & $1.51(1.22-1.88)^{* * *}$ \\
\hline Low & 444 & 52.5 & & $3.15(2.41-4.11)^{* * *}$ \\
\hline \multicolumn{5}{|l|}{ Social ties } \\
\hline \multicolumn{5}{|l|}{ Relatives donating } \\
\hline No & 814 & 34.4 & $\mathrm{df}=1, \chi^{2}=12.4 * * *$ & reference category \\
\hline Yes & 1,888 & 27.6 & & $0.81(0.66-0.99)^{*}$ \\
\hline \multicolumn{5}{|l|}{ Friends donating } \\
\hline No & 521 & 38.6 & $\mathrm{df}=1, \chi^{2}=24.5^{* * *}$ & reference category \\
\hline Yes & 2,181 & 27.6 & & $0.69(0.55-0.86)^{* *}$ \\
\hline \multicolumn{5}{|c|}{ Other blood service } \\
\hline \multicolumn{5}{|c|}{$\begin{array}{l}\text { Competing blood service } \\
\text { available }\end{array}$} \\
\hline No & 2,555 & 29.2 & $\mathrm{df}=1, \chi^{2}=5.3^{*}$ & reference category \\
\hline Yes & 147 & 38.1 & & $1.85(1.25-2.73)^{* *}$ \\
\hline \multicolumn{5}{|c|}{ Donated outside Baden-Württemberg or Hesse } \\
\hline No & 2,658 & 29.5 & $\mathrm{df}=1, \chi^{2}=2.7$ & reference category \\
\hline Yes & 44 & 40.9 & & $1.44(0.73-2.83)$ \\
\hline $\mathrm{N}$ & 2,702 & & 2,702 & 2,702 \\
\hline Nagelkerkes $\mathrm{R}^{2}$ & & & & 0.25 \\
\hline \multicolumn{5}{|c|}{$\begin{array}{l}\text { * } \mathrm{p}<0.05 ; * * \mathrm{p}<0.01 ; * * * \mathrm{p}<0.001 \text {. } \\
\text { a After the initial donation. } \\
\text { 'The dependent variable has two categories: 'being lapsed }=1 \text { ' or 'being active }=0 \text { '. Interpretation example: Adjusting fo } \\
\text { donor characteristics, the last donation experience, social ties, and access to other blood services the risk of being lapsed } \\
\text { four years after the initial donation of not employed donors was } 1.73 \text { times higher as the risk of employed donors. } \\
\text { These differences were significant with } \mathrm{p}<0.001 \text {. }\end{array}$} \\
\hline
\end{tabular}


Fig. 1. Percentage of lapsed donors who rated each reason as important or very important in different age groups. Stars are indicating significant differences between both age groups with $\mathrm{p}<0.05$.

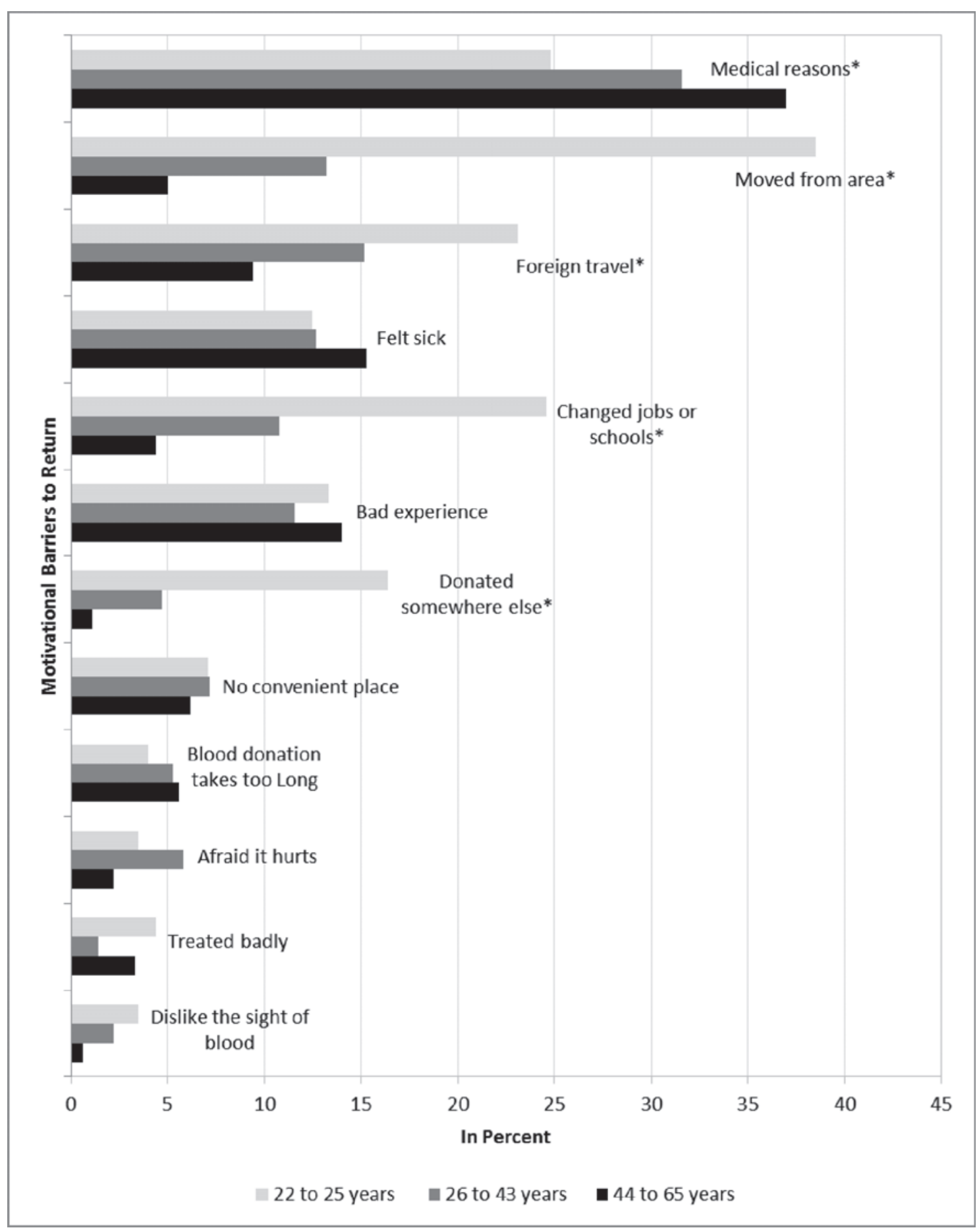

ferred due to temporary conditions like low hemoglobin or hematocrit values [10]. Blood services may reactivate those donors, pointing out that only few donors who once have donated successfully are permanently deferred. Our results suggest that especially older donors may be interested in such information addressing health concerns. In contrast, younger donors may be more interested in deferral periods due to travel to foreign countries.

The current findings also suggest that donors who become lapsed donors at the beginning of their donor career only had very few donation experiences and that many of them were dissatisfied with the last experience. Adverse events, long waiting times, unfriendly staff, inconvenient location, or anxiety have been discussed as reasons for dissatisfaction [17]. It may help lapsed donors to know that the blood service is interested in improving its services and regrets any inconvenience. It may also be important to communicate that severe complications after WB donation like fainting are rare and can easily be prevented in many cases [18]. 
The present findings are consistent with other research results which investigated that women, younger donors, and donors who were dissatisfied with last donation were more likely to become lapsed donors [4, 5]. Furthermore, bivariate results presented in table 2 supports the findings of a Canadian study [4] which showed that higher educated FT donors are more likely to become lapsed donors. However, after adjusting for the number of moves and several other factors in the multivariate analysis of our study, the association between donor status and educational level disappeared. Therefore, reactivation campaigns should not overestimate the educational level of the donor, but blood services must consider that higher educated donors are more likely to move especially when they are younger and therefore have a higher risk of becoming lapsed donors.

Interestingly, the importance of several barriers has been judged differently in a previous study using a similar list of potential barriers. Schreiber et al. [9] found that not having a convenient place to donate, bad treatment, and poor staff skills were major barriers for lapsed US donors who had not donated in the last 2 or 3 years [9]. The lapsed donors of the German Red Cross Blood Service rated convenience and bad treatment only as minor barriers and mentioned medical reasons and having moved to another city as more important. This finding suggests that the importance of barriers of lapsed donors may vary considerably between countries, and blood services and may be influenced by cultural norms. Thus there is a definite need for donor surveys to guide reactivation campaigns.

These results also have implications for blood services that are interested in preventing donor loss. Our findings with respect to observing low proportions of lapsed donors amongst those with friends and relatives donating regularly suggest that social ties are vital for donor retention. Encouraging active donors to remind their friends and family members to donate blood appears to be a promising strategy to support donor return. At present, the importance of family members and friends is primarily discussed in the context of donor recruitment [19]. Obviously, donor retention is also influenced by social ties.

Furthermore, our study showed that the donation frequency during the first year was the most important predictor of becoming a lapsed donor 4 years after the initial donation. These findings are consistent with a previous study which showed that the donation frequency during the first year can predict donor return, and every donation in the 12 months following the initial blood donation significantly increases the likelihood of becoming a regular blood donor [13]. Therefore, strategies to encourage FT donors to return as soon as possible are needed. Recent evidence suggests that phone calls can help to remind FT donors about upcoming opportunities and to increase donor return [20]. Furthermore, the blood services should check carefully whether the annual number of mobile collection sites in each municipality is adequate [13].

Our findings should be interpreted within the context of several limitations. First, we considered only donations collected by the German Red Cross Blood Service Baden-Württemberg - Hessen. To avoid biased results due to blood donations at other organizations, we used two indicator variables to account for competing donor recruitment activities. The analysis showed that donors living close to a competing blood service were indeed more likely to become lapsed donors, confirming previous findings [14]. Second, donors were categorized as 'lapsed' based on questionnaire data, but not on the information from the database of the German Red Cross Blood Service Baden-Württemberg - Hessen. The proportion of lapsed donors might therefore be underestimated due to social desirability bias. We decided to use a self-administered mail survey instead of personal or telephone interviews in order to minimize bias due to underreporting of being lapsed. Third, the response in our survey was higher among donors who returned for further donations (table 1). Hence, the proportion of lapsed donors is expected to be higher than the estimated $29.7 \%$ presented in this study. Fourth, lapsed donors may face additional important barriers that we did not ask for in our study. We decided to adopt a list of twelve potential barriers from a previous study and found considerable variation that underscore the need for donor survey. Qualitative studies may be a useful addition to detect further barriers and to explore the role of medical reasons which appeared to be very important for lapsed donors of the German Red Cross Blood Services.

The aim of this study was to identify characteristics of donors that had not donated in the past 2 years compared to active donors and to describe motivational factors deterring them from further blood donations using a list of potential barriers. The results showed that lapsed donors were more likely to be female, younger, not employed, having moved, dissatisfied with the last donation experience, and have no friends or relatives donating blood. In contrast to a previous study, medical reasons and moving to another city were the most frequently stated reasons that prevented lapsed donors of the German Red Cross Blood Service Baden-Württemberg - Hessen from continuing blood donation.

\section{Acknowledgement}

The authors would like to thank Daniela Griffiths for her support in preparing the English version of the manuscript.

\section{Funding}

The study was supported by the German Red Cross Blood Service of Baden-Württemberg - Hessen. Parts of the study constitute the topic of the thesis of Christian Weidmann.

\section{Disclosure Statement}

The authors declared no conflict of interest. 


\section{References}

1 Katalinic A, Peters E, Beske F, Pritzkuleit R: Projection of morbidity 2030 and 2050: Impact for the national health system and blood supply. Transfus Med Hemother 2010;37:155-159.

$\checkmark 2$ Seifried E, Klueter H, Weidmann C, Staudenmaier T, Schrezenmeier H, Henschler R, Greinacher A, Mueller MM: How much blood is needed? Vox Sang 2011; 100:10-21.

3 Duboz P, Cuneo B: How barriers to blood donation differ between lapsed donors and non-donors in France. Transfus Med 2010;20:227-236.

4 Germain M, Glynn SA, Schreiber GB, Gelinas S, King M, Jones M, Bethel J, Tu Y: Determinants of return behavior: a comparison of current and lapsed donors. Transfusion 2007;47:1862-1870.

5 Veldhuizen IJ, Doggen CJ, Atsma F, De Kort WL: Donor profiles: demographic factors and their influence on the donor career. Vox Sang 2009;97:129-138.

6 Custer B, Chinn A, Hirschler NV, Busch MP, Murphy EL: The consequences of temporary deferral on future whole blood donation. Transfusion 2007;47:1514 1523 .

7 Newman BH, Newman DT, Ahmad R, Roth AJ: The effect of whole-blood donor adverse events on blood donor return rates. Transfusion 2006;46:13741379

8 Kuruvatti J, Prasad V, Williams R, Harrison MA, Jones RP: Motivations for donating blood and reasons why people lapse or never donate in Leeds, England: a 2001 questionnaire-based survey. Vox Sang 2011;101:333-338.

9 Schreiber GB, Schlumpf KS, Glynn SA, Wright DJ, Tu Y, King MR, Higgins MJ, Kessler D, Gilcher R, Nass CC, Guiltinan AM: Convenience, the bane of our existence, and other barriers to donating. Transfusion 2006;46:545-553.

10 Mathew SM, King MR, Glynn SA, Dietz SK, Caswell SL, Schreiber GB: Opinions about donating blood among those who never gave and those who stopped: a focus group assessment. Transfusion 2007;47:729-735.

11 Ringwald J, Lange N, Rabe C, Zimmermann R, Strasser E, Hendelmeier M, Strobel J, Eckstein R: Why do some apheresis donors donate blood just once? Vox Sang 2007;93:354-362.

12 Guo N, Wang J, Ness P, Yao F, Dong X, Bi X, Mei H, Li J, He W, Lu Y, Ma H, Wen X, Huang M, Wright DJ, King M, High P, Nelson K, Shan H: Analysis of Chinese donors' return behavior. Transfusion 2011;51:523-530.

13 Schreiber GB, Sharma UK, Wright DJ, Glynn SA, Ownby HE, Tu Y, Garratty G, Piliavin J, Zuck T, Gilcher R: First year donation patterns predict long-term commitment for first-time donors. Vox Sang 2005;88:114-121.

14 Weidmann C, Schneider S, Litaker D, Weck E, Klüter H: A spatial regression analysis of German community characteristics associated with voluntary nonremunerated blood donor rates. Vox Sang 2011; DOI: 10.1111/j.1423-0410. 2011.01501.x

15 Misje AH, Bosnes V, Heier HE: Recruiting and retaining young people as voluntary blood donors. Vox Sang 2008;94:119-124.

16 AAPOR: Standard Definitions. Final Dispositions of Cases Codes and Outcome Rates for Surveys. Revised 2009. Deerfield, American Association for Public Opinion Research, 2009.

17 Ringwald J: Established ways to keep donor's interest alive. ISBT Science Series 2010;5:17-23.

18 Wieling W, France CR, van Dijk N, Kamel H, Thijs RD, Tomasulo P: Physiologic strategies to prevent fainting responses during or after whole blood donation. Transfusion 2001; DOI: 10.1111/j.1537-2995.2011.03202.x.

19 Glynn SA, Schreiber GB, Murphy EL, Kessler D, Higgins M, Wright DJ, Mathew S, Tu Y, King M, Smith JW: Factors influencing the decision to donate: racial and ethnic comparisons. Transfusion 2006;46:980-990.

20 Godin G, Amireault S, Vezina-Im LA, Germain M, Delage G: The effects of a phone call prompt on subsequent blood donation among first-time donors. Transfusion 2011; DOI: 10.1111/j.1537-2995.2011.03204.x. 